$\underline{\text { Original Articles }}$

\title{
Aetiology and mortality predictors in critically ill neonates with acute kidney injury at a tertiary health centre: A prospective observational study
}

\author{
*Rajkumar M Meshram¹, Avinash T Chichkhede ${ }^{2}$ \\ Sri Lanka Journal of Child Health, 2021; 50(3): 377-384
}

\begin{abstract}
Background: In India, the incidence of acute kidney injury (AKI) ranges from $4.2 \%$ to $37.1 \%$, with a $60 \%$ mortality in neonates.
\end{abstract}

Objectives: To determine the aetiology and outcome of AKI in critically ill neonates.

Method: A 1 year prospective observational study was undertaken at a tertiary institute on critically ill neonates who fulfilled the inclusion criteria. AKI was diagnosed based on a plasma creatinine level $>1.5 \mathrm{mg} / \mathrm{dl}$ and the plasma creatinine was repeated at 72 hours and on the 7th day of diagnosis. Aetiology and risks of mortality were analysed.

Results: Male: female ratio was 1.55:1. Around $60 \%$ neonates were term and $64.6 \%$ had normal birth weight. Anaemia was the commonest maternal illness followed by hypertension. Sepsis was associated with $60 \%$ neonates with AKI followed by dehydration (19.2\%) and birth asphyxia (14.6\%). All neonates with proven sepsis and HIE stage III succumbed. Escherichia coli was the commonest isolate in the septic neonate. Mortality rate was $33.1 \%$. Presence of maternal anaemia, hypertension, oliguria, high mean serum creatinine, acidosis and hyponatraemia were related to a higher mortality. Likewise, sepsis, shock, asphyxia, respiratory distress syndrome, use of mechanical ventilation and need of renal replacement therapy in neonates were significantly associated with a high mortality. Sepsis, birth asphyxia and use of mechanical ventilation were the independent risk factors of mortality.

${ }^{1}$ Associate Professor, ${ }^{2}$ Postgraduate Student, Department of Paediatrics, Government Medical College, Nagpur, Maharashtra, India

*Correspondence: dr_rajmeshram@rediffmail.com

https://orcid.org/0000-0003-3214-188X

(Received on 28 May 2020: Accepted after revision on 24 July 2020)

The author declares that there are no conflicts of interest

Personal funding was used for the project.

Open Access Article published under the Creative

Commons Attribution CC-BY (cc) (P)
Conclusions: Sepsis was most common aetiological factor for AKI followed by dehydration and birth asphyxia. The mortality rate was $33.1 \%$. Sepsis, birth asphyxia and use of mechanical ventilation were the independent risk factors of mortality.

DOI: http://doi.org/10.4038/sljch.v50i3.9684

(Key words: Acute kidney injury, critically ill neonate, risk factors of mortality, sepsis)

\section{Introduction}

Acute kidney injury (AKI) is defined as an acute deterioration in renal function due to abrupt reduction in glomerular filtration rate (GFR) resulting in derangement in fluid, electrolytes, and waste products ${ }^{1}$. Most common form of AKI is prerenal $(85 \%)$ due to renal hypoperfusion, followed by renal $(11 \%)$ due to intrinsic damage to renal parenchyma, and post-renal $(3 \%)$ caused by intrinsic obstruction ${ }^{2}$. Recent definitions of AKI are based on the degree of increase in serum creatinine level (more than a single absolute cut-off value), and urine output ${ }^{3}$.

Due to lack of precise definition, the real prevalence of AKI in the neonate is unknown, and varies from $1.5 \%$ to $56 \%$, associated with higher mortality and consuming more expenses due to long hospital stay-7. In India, AKI incidence ranges from $4.2 \%$ to $37.1 \%$, with a $60 \%$ mortality in neonates ${ }^{8-10}$. Presence of shock, sepsis, use of mechanical ventilation and need of renal replacement therapy were associated with higher mortality in neonates with $\mathrm{AKI}^{11-15}$. Most neonatal caretakers are unaware about the current standard definition, risk factors associated with AKI and the risk of chronic kidney disease in preterm infants ${ }^{16}$. So, the current study was conducted to determine the aetiology and predictors of mortality in critically ill neonates with AKI.

\section{Objectives}

To determine the aetiology and outcome of AKI in critically ill neonates.

\section{Method}

A prospective observational study was undertaken at the neonatal intensive care unit (NICU) of a 
tertiary care government teaching hospital over a period of one year from March 2018 to February 2019. Our NICU has adequate faculty trained nursing staff and postgraduate residents, is equipped with sufficient phototherapy units, multipara monitors, ventilation care and facilities for dialysis/surfactant therapy for neonates and accommodates 20 neonates at a given time.

All critically ill neonates, between 0 and 28 days of life, diagnosed to have AKI on admission or who developed AKI during their hospital stay, irrespective of gestational age, sex, birth weight or postnatal age, were included. AKI was defined as a serum creatinine level $\geq 1.5 \mathrm{mg} / \mathrm{dl}$ at any time during hospital stay within the first 28 days of life. Neonates with multiple congenital anomalies, chromosomal anomalies, antenatally diagnosed hydronephrosis, mothers with acute or chronic renal diseases and neonates who died within 24 hours of life were excluded.

Sample size of 106 was calculated with expected proportion of 0.77 , absolute precision of $8 \%$ and confidence interval of $95 \%$ by using the following formula: $\mathrm{N}=\mathrm{Z}^{2}{ }_{1-\alpha} \mathrm{p}(1-\mathrm{p}) / \mathrm{d}^{2}$ where $\mathrm{N}=$ no. of sample size, $\alpha=$ level of significance, Z1$\alpha=$ corresponding normal standard variant, $\mathrm{p}=$ anticipated proportion, and $\mathrm{d}=$ absolute precision. We enrolled 130 critically ill neonates for the study according to the inclusion and exclusion criteria, after obtaining written informed consent from parents or caretakers. Serum creatinine levels were measured in all clinically suspected cases of AKI or as a part of routine screening protocol (those admitted before 72 hours of life were screened at 72 hours of life and those admitted after 72 hours were screened at admission). AKI was diagnosed on the basis of the serum creatinine level.

Data were collected following admission, from either the mother or caregiver in a structured data sheet. Maternal details, including age, gravida/ parity status, details of antenatal care, obstetric complications, and mode of delivery were recorded. Socioeconomic status of parents was classified on the basis of Modified Kuppuswamy scale $^{17}$. Neonatal data included gestational age (GA), assessed by either menstrual history of mother, available ultrasound report or by New Ballard Scoring ${ }^{18}$, gender, birth weight, age at admission, and the day of life when diagnosis of AKI was recorded. The neonates were classified as appropriate for GA (AGA), small for GA (SGA), and large for GA in accordance with the revised Fenton growth charts.

Dehydration was assessed by measuring the admission weight of the neonate with respect to the birth weight and other clinical signs of dehydration.
A diagnosis of birth asphyxia was made on the basis of the National Neonatal Perinatal Database Network definition. Birth asphyxiated babies were classified according to Sarnat and Sarnat staging in babies at $\geq 36$ weeks' gestation and hypoxicischaemic encephalopathy (HIE) into Grades 0 and I as no or mild asphyxia, Grades II and III as moderate to severe asphyxia. Respiratory distress was diagnosed in the presence of at least 2 of the following criteria: (1) respiratory rate $>60 / \mathrm{min}$ recorded for at least $1 \mathrm{~min}$, (2) chest indrawing, and (3) expiratory grunt/groaning. Clinical sepsis was defined as a neonate having symptoms and/or signs of sepsis with maternal risk factors of infection. Probable sepsis was clinical sepsis with a positive septic screen and confirmed sepsis was defined as with the growth of causative organism in blood culture. Urine output was monitored and recorded from the time of diagnosis of AKI for the following 48 hours. Urine output was measured by weighing the wet nappies in un-catheterised neonates and catheterization was done if an infant has failed to pass urine by $36-48$ hours of age, and was calculated over a period of 24 hours in the form of $\mathrm{mL} / \mathrm{kg} / \mathrm{hr}$.

Serum creatinine levels were estimated with an AUDXC700 automated analyser (Beckman Coulter USA) by the principle of Jaffe's reaction. Serum creatinine more than $1.5 \mathrm{mg} / \mathrm{dl}$ was considered as a case of AKI. Serum creatinine levels were measured at 24 hours, 72 hours and on day 7 of diagnosis. Serum urea and electrolytes were repeated in the next 24-48 hours according to the clinical condition of the neonates. Arterial blood gas analysis was performed by radial artery puncture on the Eschweiler gas analyser at the time of diagnosis of AKI and it was repeated over the next 24-48 hours as required. Urine microscopy was performed on suprapubic aspirated urine sample to detect the presence of pus cells and red blood cells; urine culture was also performed. Ultrasonography of the abdomen was performed to visualize the kidney, ureter and bladder in all cases of AKI to rule out obstructive causes of AKI.

The neonates were managed according to the standard hospital protocols with judicious fluid and electrolyte administration, minimization of nephrotoxin exposure, and peritoneal dialysis.

Ethical issues: Ethical approval was obtained from the Institutional Ethical Committee of Government Medical College, Nagpur, Maharashtra, India (No. 1107 EC/Pharmac/GMC/NGP Date: 14/02/2018). Written informed consent was obtained from the parents of the neonates.

Statistical analysis: Data were entered into Microsoft Excel sheet and analysed using STATA 
version 14 (Texas USA). Data as regards numerical variables were presented as percentage, mean, median, and standard deviation. Categorical data were compared using Pearson's Chi-square or Fisher's exact test. Student t-test was used for continuous variables. Logistic regression analysis was used to assess correlation between each independent variable and mortality and relative risk (RR) were assessed with a 95\% confidence interval. $\mathrm{p}<0.05$ was considered statistically significant.

\section{Results}

One hundred and thirty critically ill neonates with AKI were studied. The baseline characteristics of the study population are shown in Table 1 .

Table 1: Baseline characteristics of the study population $(n=130)$

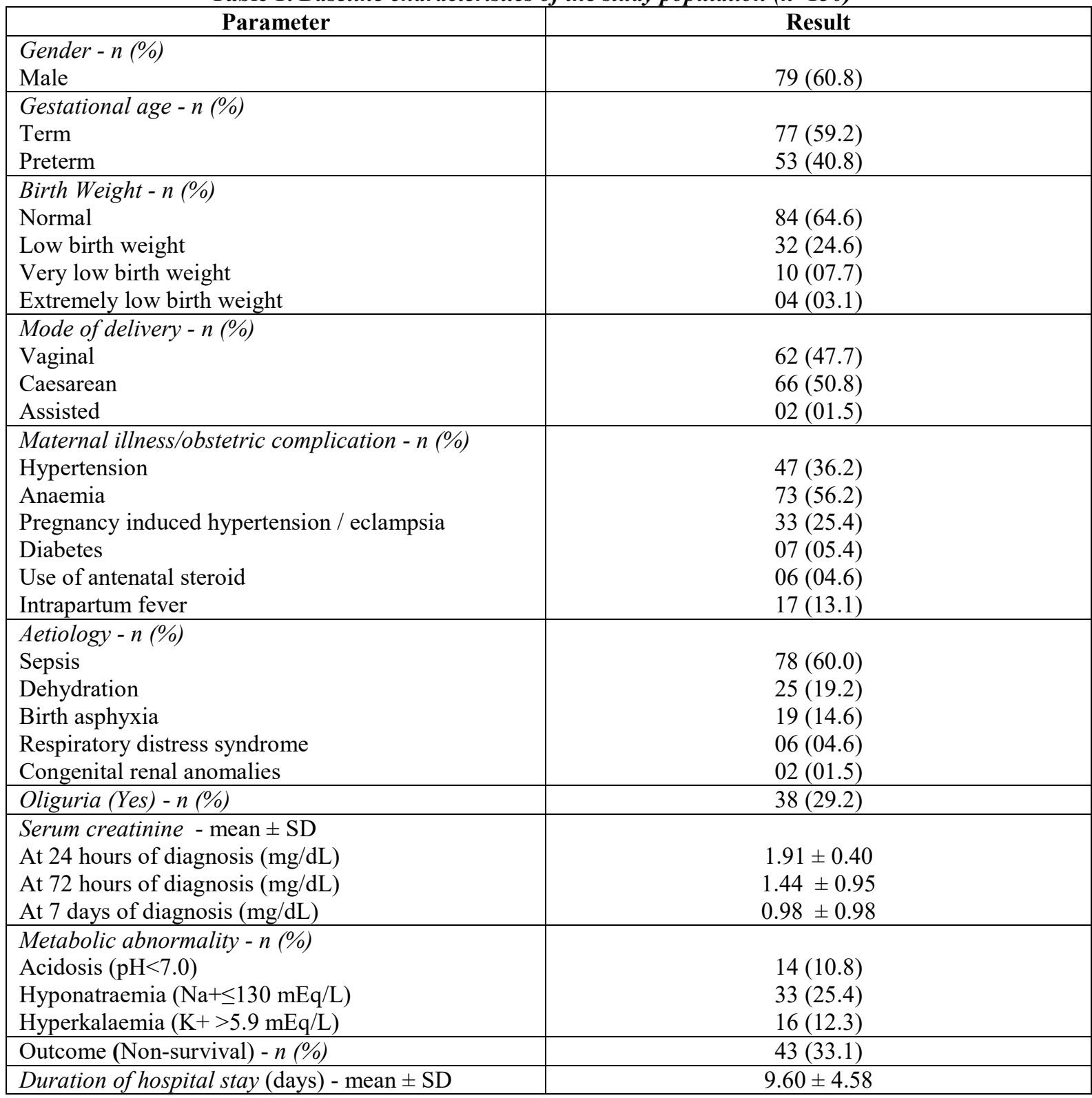

Seventy seven $(59.2 \%)$ neonates were born at term and $84(64.6 \%)$ had normal birth weight. Male: female ratio was $1.55: 1$. Sixty two $(47.7 \%)$ neonates were delivered by the vaginal route and $66(50.8 \%)$ by caesarean section. Anaemia was the most common maternal illness while 47 (36.2\%) mothers also had hypertension during pregnancy. Pregnancy induced hypertension/eclampsia was the commonest obstetric complication during pregnancy.

Oliguria was observed in $38(29.2 \%)$ neonates. Mean serum creatinine levels at 24 hours, 72 hours and $7^{\text {th }}$ day of diagnosis were $1.91 \pm 0.40 \mathrm{mg} / \mathrm{dL}$, $1.44 \pm 0.95 \mathrm{mg} / \mathrm{dL}$ and $0.98 \pm 0.98 \mathrm{mg} / \mathrm{dL}$ respectively and the difference of mean creatinine level between the survival and non-survival was statistically 
significant $(\mathrm{p}<0.0001)$. Severe acidosis $(\mathrm{pH}<7.0)$, hyponatraemia (serum sodium $\leq 135 \mathrm{mEq} / \mathrm{L}$ ), and hyperkalaemia (serum potassium $>5.9 \mathrm{mEq} / \mathrm{L}$ ) were seen in $14(10.8 \%), 33(25.4 \%)$ and $16(12.3 \%)$ neonates, respectively. Severe acidosis $(\mathrm{p}=0.04)$ and hyponatremia $(\mathrm{p}<0.0001)$ were significantly associated with mortality but hyperkalaemia was non-significant. Average duration of hospital stay was $9.60 \pm 4.58$ days, but average duration of hospital stay in non-survival neonates was shorter
(6.32 \pm 4.62 days) compared to survival (11.22 \pm 3.62 days) and this difference was statistically significant $(\mathrm{p}<0.0001)$.

Sepsis was diagnosed in $78(60 \%)$ critically ill neonates, followed by dehydration in 25 (19.2\%) and birth asphyxia in $19(14.6 \%)$ neonates. Among septicaemic neonates, $37(47.4 \%)$ were clinical sepsis while $27(34.6 \%)$ were probable sepsis (Figure 1).

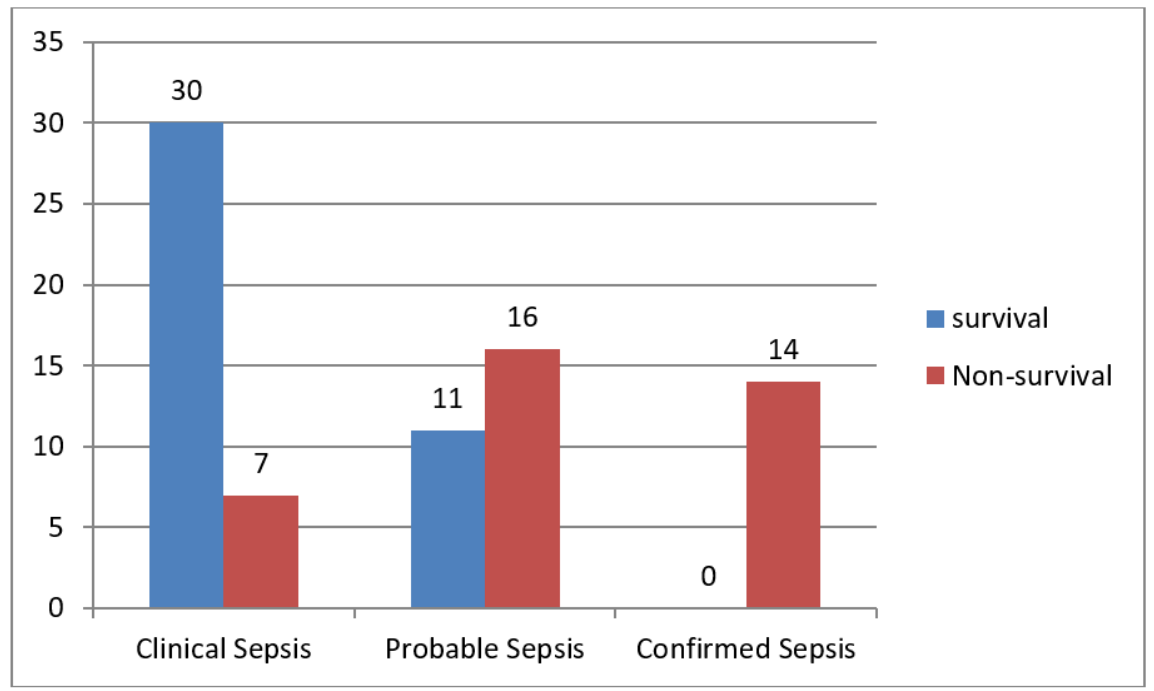

Figure 1: Distribution of septic neonates in acute kidney injury

Microorganisms were isolated in 14 (18\%) septic neonates. Escherichia coli was isolated in 5 $(35.7 \%)$, Klebsiella and acinetobacter in $3(21.4 \%)$ each and fungal (candida) species in one extremely low birth weight neonate (Figure 2).

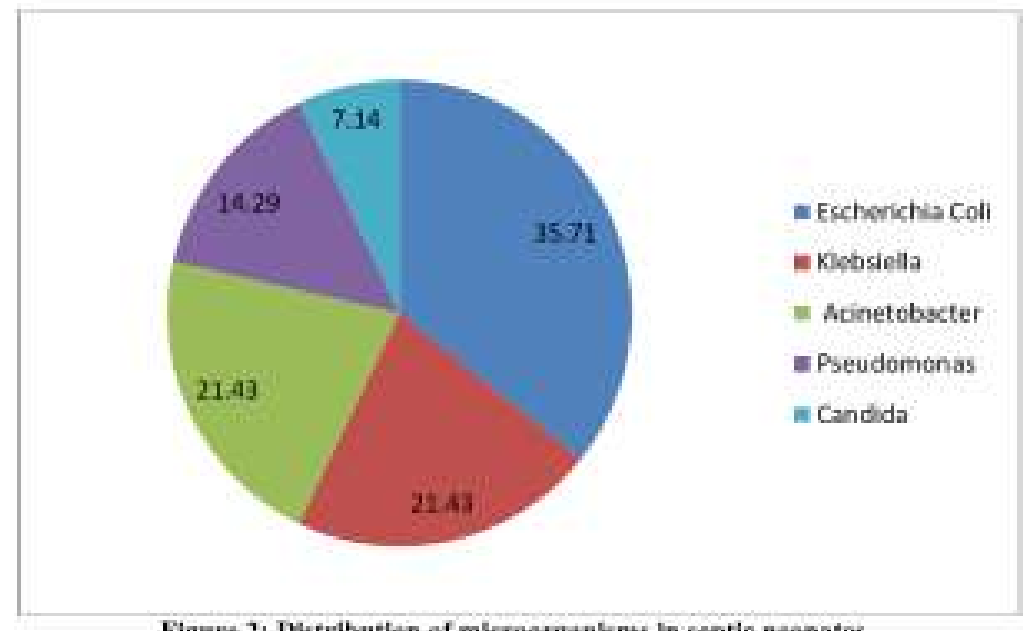

Figure 2: Distribution of microerganksns in septic neonates

All the culture positive septic neonates succumbed. Among the asphyxiated neonates $4(21.1 \%)$ had HIE stage I, 8 (42.1\%) had HIE stage II and 7 $(36.8 \%)$ were diagnosed to have HIE stage III. All neonates with HIE stage III died.

Table 2 shows the different parameters affecting mortality. Eighty seven $(66.9 \%)$ neonates were discharged while mortality was observed in 43 (33.1\%) neonates. There was no difference in mortality by gender, gestational age, birth weight, mode of delivery, antenatal steroid use, maternal fever, presence of dehydration /congenital renal anomalies or hyperkalaemia. However, maternal anaemia $(p<0.0001)$, hypertension $\quad(p=0.02)$; neonates with sepsis $(\mathrm{p}<0.0001)$, respiratory 
distress syndrome $(\mathrm{p}=0.001)$, asphyxiated neonates $(\mathrm{p}-0.005)$ and presence of oliguria $(\mathrm{p}-0.02)$, shock $(\mathrm{p}<0.0001)$, use of mechanical ventilation $(\mathrm{p}<0.0001)$ and requirement of renal replacement therapy $(\mathrm{p}=0.003)$ were significantly associated with higher mortality. Presence of sepsis, shock and use of mechanical ventilation were the independent risk factors for mortality on multiple regression analysis (Table 3 )

Table 2: Risk factors of mortality in neonate with acute kidney injury (Univariate)

\begin{tabular}{|c|c|c|c|}
\hline Variables & Survival $(n=87)$ & Non-survival $(n=43)$ & p-value \\
\hline $\begin{array}{l}\text { Gender - } n(\%) \\
\text { Male }\end{array}$ & $51(58.6)$ & $28(65.1)$ & 0.6 \\
\hline $\begin{array}{l}\text { Gestational age }-n(\%) \\
\text { Term } \\
\text { Preterm }\end{array}$ & $\begin{array}{l}52(59.8) \\
35(40.2)\end{array}$ & $\begin{array}{l}25(58.1) \\
18(41.9)\end{array}$ & 0.85 \\
\hline $\begin{array}{l}\text { Birth Weight }-n(\%) \\
<2500 \mathrm{~g} \\
2500 \mathrm{~g} \text { or more }\end{array}$ & $\begin{array}{l}57(65.5) \\
30(34.5)\end{array}$ & $\begin{array}{l}27(62.8) \\
16(37.2)\end{array}$ & 0.91 \\
\hline Oliguria (present) $-n(\%)$ & $20(23.0)$ & $18(41.89)$ & 0.02 \\
\hline $\begin{array}{l}\text { Mode of delivery }-n(\%) \\
\text { Vaginal } \\
\text { Caesarean } \\
\text { Assisted }\end{array}$ & $\begin{array}{l}38(43.7) \\
41(47.1) \\
01(01.2)\end{array}$ & $\begin{array}{l}24(55.8) \\
25(58.1) \\
01(02.3)\end{array}$ & $\begin{array}{c}0.26 \\
0.31 \\
0.6\end{array}$ \\
\hline $\begin{array}{l}\text { Maternal illness/obstetric complication }-n(\%) \\
\text { Hypertension } \\
\text { Anaemia } \\
\text { Pregnancy induced hypertension / eclampsia } \\
\text { Diabetes } \\
\text { Use of antenatal steroid } \\
\text { Intrapartum fever }\end{array}$ & $\begin{array}{l}25(28.7) \\
38(43.7) \\
18(20.7) \\
04(04.6) \\
04(04.6) \\
08(09.2)\end{array}$ & $\begin{array}{l}22(51.2) \\
35(81.4) \\
15(34.9) \\
03(07.0) \\
02(04.7) \\
09(20.9)\end{array}$ & $\begin{array}{c}0.02 \\
<0.0001 \\
0.12 \\
0.87 \\
0.98 \\
0.1 \\
\end{array}$ \\
\hline $\begin{array}{l}\text { Aetiology }-n(\%) \\
\text { Sepsis } \\
\text { Birth asphyxia } \\
\text { Dehydration } \\
\text { Respiratory distress syndrome } \\
\text { Congenital renal anomalies } \\
\text { Shock } \\
\text { Use of mechanical ventilation } \\
\text { Need of peritoneal dialysis }\end{array}$ & $\begin{array}{c}41(47.1) \\
07(08.1) \\
13(14.9) \\
0 \\
02(02.3) \\
04(04.6) \\
07(08.1) \\
03(03.5) \\
\end{array}$ & $\begin{array}{c}37(86.1) \\
12(27.9) \\
12(27.9) \\
06(14.0) \\
0 \\
14(32.6) \\
21(48.8) \\
09(20.9)\end{array}$ & $\begin{array}{c}<0.0001 \\
0.005 \\
0.12 \\
0.001 \\
0.8 \\
<0.0001 \\
<0.0001 \\
0.003\end{array}$ \\
\hline $\begin{array}{l}\text { Serum Creatinine - mean } \pm S D \\
\text { At } 24 \text { hour of diagnosis }(\mathrm{mg} / \mathrm{dL}) \\
\text { At } 72 \text { hours of diagnosis }(\mathrm{mg} / \mathrm{dL}) \\
\text { At } 7 \text { days of diagnosis }(\mathrm{mg} / \mathrm{dL})\end{array}$ & $\begin{array}{c}1.74 \pm 0.12 \\
0.99 \pm 0.58 \\
0.4 \pm 0.11\end{array}$ & $\begin{array}{l}2.62 \pm 0.69 \\
2.5 \pm 0.28 \\
2.3 \pm 0.12\end{array}$ & $\begin{array}{l}<0.0001 \\
<0.0001 \\
<0.0001\end{array}$ \\
\hline $\begin{array}{l}\text { Metabolic abnormality }-n(\%) \\
\text { Acidosis }(\mathrm{pH}<7.0) \\
\text { Hyponatraemia }(\mathrm{Na}+\leq 130 \mathrm{mEq} / \mathrm{L}) \\
\text { Hyperkalaemia }(\mathrm{K}+>5.9 \mathrm{mEq} / \mathrm{L})\end{array}$ & $\begin{array}{l}06(06.9) \\
13(14.9) \\
09(10.3)\end{array}$ & $\begin{array}{l}08(18.6) \\
20(46.5) \\
07(16.3)\end{array}$ & $\begin{array}{c}0.04 \\
<0.0001 \\
0.49\end{array}$ \\
\hline Duration of stay (days) - mean $\pm S D$ & $11.22 \pm 3.62$ & $6.32 \pm 4.62$ & $<0.0001$ \\
\hline
\end{tabular}

Table 3: Independent predictors of mortality in neonates with acute kidney injury

\begin{tabular}{|l|c|c|c|}
\hline \multicolumn{1}{|c|}{ Variable } & Adjusted OR & 95\% confidence interval & p-value \\
\hline Sepsis & 14.22 & $3.47-58.29$ & $<0.001$ \\
\hline Birth asphyxia & 5.90 & $1.18-29.57$ & 0.03 \\
\hline Mechanical ventilation & 9.56 & $2.91-31.30$ & $<0.001$ \\
\hline
\end{tabular}

\section{Discussion}

Although, premature neonates are more prone to AKI due to incomplete nephrogenesis and low nephron number, in our study $59 \%$ were born at term and more than $60 \%$ had normal birth weight. Similar observations were made by Pradhan DD, et $a l^{19}$ who reported that $58 \%$ of term babies and $46 \%$ of normal birth weight babies had AKI. We observed a male to female ratio of $1.55: 1$. This is similar to results by various researchers who observed that males were more frequently affected 
by $\mathrm{AKI}^{7,20,21}$. However, Agras PI, et al ${ }^{22}$ reported a female predominance.

Various researchers reported that maternal variables like pregnancy induced hypertension, multi-fetal gestation, use of antenatal steroids and polyhydramnios were associated with an increased risk of AKI in neonates ${ }^{7,11,12,15}$. In our study the mortality was significantly higher in neonates born to mothers with anaemia and hypertension. We observed that neonatal sepsis was the commonest cause of neonatal AKI, accounting for $60 \%$ of neonates which is comparable with studies done by Kapoor K, et al $(61.3 \%)^{20}$ and Choudhary $\mathrm{S}$, et al $(65.5 \%)^{23}$ while some authors noted that a higher number of septic neonates had $\mathrm{AKI}^{19,21,25}$.

In the present study, birth asphyxia was responsible for AKI in $14.6 \%$ neonates. It was $52.8 \%$ in a study by Halder $\mathrm{S}$, et $a l^{24}$ and $41.7 \%$ in a study by Kaur $\mathrm{S}$, et $a l^{25}$. Selewski DT, et $a l^{26}$ reported that $38 \%$ of neonates who had undergone therapeutic hypothermia for perinatal asphyxia, had AKI. Other causes of AKI in our study were respiratory distress syndrome in $4.6 \%$ and renal anomalies in $1.5 \%$ neonates. Bolat $\mathrm{F}$, et $a l^{15}$ found that $38.1 \%$ neonates, who had respiratory distress syndrome treated with surfactant therapy, had AKI, while a recent study by Momtaz et $a l^{4}$ reported RDS to be the third common association with AKI (34.6\%) after sepsis and dehydration. However, Bansal et $a l^{8}$ could not find a significant number of RDS cases in the AKI group compared to the control group. In the present study, oliguric AKI was observed in $29.2 \%$ neonates and most of the oliguric neonates were dehydrated and septic. Similar to our study, other researchers observed higher mortality (47.4\%) in oliguric neonates ${ }^{15,19}$.

The mortality rate in the current study was $33.1 \%$, similar to the $36.7 \%$ in the study by Momtaz HE, et $a l^{4}$. A multinational, multicentre, observation cohort study ${ }^{7}$ found that neonates with AKI had a higher mortality compared to those without AKI. Similarly, a higher mortality (21\%) was observed by Halder $\mathrm{S}$, et $a l^{24}$ in infants with AKI compared to $10 \%$ in infants without $\mathrm{AKI}$.

Bolat $\mathrm{F}$, et $a l^{15}$ reported that the use of mechanical ventilation, requirement of peritoneal dialysis, presence of anuria, very low birth weight, bronchopulmonary dysplasia, use of inotropic support, high mean creatinine, high blood urea and low sodium level were the risk factors of mortality in neonates with AKI. In a study by Momtaz HE et $a l^{4}$, higher mortality was noted in term neonates, female gender, birth weight $>2500 \mathrm{~g}$, oliguric status and neonates who required dialysis while Pradha $\mathrm{DD}$, et $a l^{19}$ demonstrated that intrinsic AKI, need of mechanical ventilation and dialysis were associated with higher mortality. In our study, the presence of oliguria/acidosis/hyponatremia, high mean serum creatinine level, presence of sepsis/shock, neonates with birth asphyxia/ respiratory distress syndrome, use of mechanical ventilation and requirement of renal replacement therapy were associated with significantly higher mortality. In our study most of the neonates with AKI died due to multi-organ failure secondary to the underlying diseases rather than renal failure.

\section{Conclusions}

Sepsis was the most common underlying clinical condition followed by dehydration and birth asphyxia. The mortality was $33.1 \%$. Oliguric AKI was observed in 29.2\% neonates. Presence of sepsis, birth asphyxia and use of mechanical ventilation were the independent risk factors of mortality.

\section{References}

1. Jetton GJ, Askenazi DJ. Acute kidney injury in neonate. Clinical Perinatology 2014; 41(3): 487-502. https://doi.org/10.1016/j.clp.2014.05.001 PMid: 25155722

2. Nada A, Bonachea EM, Askenazi D. Acute kidney injury in the fetus and neonate. Seminars in Fetal Neonatal Medicine 2017; 22(2): 90-7.

https://doi.org/10.1016/j.siny.2016.12.001

PMid: 28034548 PMCid: PMC5373985

3. Zappitelli M, Ambalavanan N, Askenazi DJ, Moxey-Mims MM, Kimmel PL, Star $\mathrm{RA}$, et al. Developing a neonatal acute kidney injury research definition: a report from the NIDDK neonatal AKI workshop. Pediatric Research 2017; 82(4); 569-73. https://doi.org/10.1038/pr.2017.136 PMid: 28604760

4. Momtaz HE, Sabzehei MK, Rasuli B, Torabian S. The main aetiologies of acute kidney injury in the newborns hospitalized in the neonatal intensive care unit. Journal of Clinical Neonatology 2014; 3(2): 99102.

https://doi.org/10.4103/2249-4847.134691

PMid: 25024976 PMCid: PMC4089136

5. Shalaby MA, Sawan ZA, Nawawi E, Alsaedi S, Al-Wassia H, Kari JA. Incidence, risk factors, and outcome of neonatal acute kidney injury: a prospective cohort study. Pediatric Nephrology 2018; 33(9):1617-24. 
https://doi.org/10.1007/s00467-018-39667

PMid: 29869723

6. Matyanga PKMJ, Kandawasvika GQ, Muchemwa LK, Mujuru HA. Prevalence of acute kidney injury in neonate admitted at a referral hospital, Harare, Zimbabwe. Central African Journal of Medicine 2013; 59(1-4):1-6.

7. Jetton JG, Boohker LJ, Sethi SK, Wazir S, Rohatgi S, Soranno DE, et al on behalf of the Neonatal Kidney Collaborative (NKC). Incidence and outcomes of neonatal acute kidney injury (AWAKEN): a multicentre, multinational, observational cohort study. Lancet Child and Adolescent Health 2017; 1(3):184-94. https://doi.org/10.1016/S23524642(17)30 069-X

8. Bansal SC, Nimbalkar AS, Kungwani AR, Patel DV, Sethi AR, Nimbalkar SM. Clinical profile and outcome of newborns with acute kidney injury in a level 3 neonatal unit in Western India. Journal of Clinical and Diagnostic Research 2017; 11: SC01-4.

9. Katariya KL, Pandya NK. Clinical profile of neonates with acute renal injury in neonatal intensive care unit at GMERS Medical College and General Hospital, Gotri, Vadodara, Gujarat, India. International Journal of Contemporary Pediatrics 2019; 6(3): 1136-42. https://doi.org/10.18203/23493291.ijcp20 192000

10. Patel A, Sharma D, Shastri S. Sharma P. Acute renal failure in critically ill newborn increases the risk of death: a prospective observational study from India. Journal of Maternal-Fetal and Neonatal Medicine 2016; 29(17): 2878-82.

11. Selewski DT, Charlton JR, Jetton JG, Guillet R, Mhanna MJ, Askenazi DJ, et al. Neonatal acute kidney injury. Pediatrics 2015; 136(2): e463-e475. https://doi.org/10.1542/peds.2014-3819

PMid: 26169430

12. Ghobrial EE, Elhouchi SZ, Elttawy SS, Beshara LO. Risk factors associated with acute kidney injury in newborns. Saudi
Journal of Kidney Diseases and Transplantation 2018; 29(1): 81-7. https://doi.org/10.4103/1319-2442.225179 PMid: 29456211

13. Mwamanenge NA, Assenga E, Furia FF. Acute kidney injury among critically ill neonates in a tertiary hospital in Tanzania; prevalence, risk factors and outcome. PLoS ONE 2020; 15(2): e0229074. https://doi.org/10.1371/journal.pone.0229 074

PMid: 32053686 PMCid: PMC7018051

14. Mathur NB, Agarwal HS, Maria A. Acute renal failure in neonatal sepsis. Indian Journal of Pediatrics 2006; 73(6): 499502.

https://doi.org/10.1007/BF02759894

PMid: 16816511

15. Bolat F, Comert S, Bolat G, Kucuk O, Can E, Bulbul A, et al. Acute kidney injury in a single neonatal intensive care unit in Turkey. World Journal of Pediatrics 2013; 9(4): 323-9. https://doi.org/10.1007/s12519-012-03713

PMid: 24235066

16. Sethi SK, Agrawal G, Wazir S, Rohatgi S, Iyengar A, Chakraborty R, et al. Neonatal acute kidney injury: a survey of perceptions and management strategies amongst paediatricians and neonatologists. Frontiers in Pediatrics 2020; 7: 553. https://doi.org/10.3389/fped.2019.00553 PMid: 32010651 PMCid: PMC6972501

17. Saleem SM. Modified Kuppuswamy socioeconomic scale updated for the year 2019. Indian Journal of Forensic and Community Medicine 2019; 6(1):1-3. https://doi.org/10.18231/23946776.2019.0 001

18. Ballard JL, Khoury JC, Wedig K, Wang L, Eilers-Walsman BL, Lipp R. New Ballard score, expanded to include extremely premature infants. Journal of Pediatrics 1991; 119(3): 417-23. https://doi.org/10.1016/S00223476(05)82 056-6

19. Pradhan DD, Meher BK, Panda SK, Samal D. Prevalence and factors affecting prognosis in neonates with acute kidney 
injury in neonatal intensive care unit. Journal of Clinical Neonatology 2018; 7(4): 237-42.

https://doi.org/10.4103/jen.JCN_51_18

20. Kapoor K, Jajoo M, Dabas V. Predictors of mortality in out-born neonates with acute renal failure; an experience of a single centre. Iranian Journal of Pediatrics 2013; 23(3): 321-6.

21. El-Badawy AA, Makar S, Abdel-Razek AA, Elaziz DA. Incidence and risk factors of acute kidney injury among the critically ill neonates. Saudi Journal of Kidney Diseases and Transplantation 2015; 26(3): 549-55.

https://doi.org/10.4103/1319-2442.157362

PMid: 26022026

22. Agras PI, Tarcn A, Baskin E, Cengiz N, Gurakan B, Saatci U. Acute renal failure in the neonatal period. Journal of Renal Failure 2004; 26(3): 305-9.

https://doi.org/10.1081/JDI-200026749

PMid: 15354981

23. Choudhary S, Verma M, Goyal K, Soni JP. Spectrum of AKI and its outcome in an out born neonatal intensive care unit: a prospective observational study. Scholars Journal of Applied Medical Sciences 2017; 5(5A):1739-43.

24. Halder S, Hoque MM, Rahman U, Sonia SF, Biswas SS. Acute kidney injury in sick neonate: incidence and outcome. Journal of Bangladesh College of Physicians and Surgeons 2017; 35(1):203.

https://doi.org/10.3329/jbcps.v35i1.32567

25. Kaur S, Jain S, Saha A, Chawla D Parmar $\mathrm{VR}$, Basu S, et al. Evaluation of glomerular and tubular renal function in neonates with birth asphyxia. Annals of Tropical Paediatrics 2011; 31(2): 129-34. https://doi.org/10.1179/146532811X1292 5735813922

PMid: 21575317

26. Selewski DT, Jordan BK, Askenazi DJ, Dechert RE, Sarkar S. Acute kidney injury in asphyxiated newborns treated with therapeutic hypothermia. Journal of Pediatrics 2013; 162(4):725-9. https://doi.org/10.1016/j.jpeds.2012.10.00 2

PMid: 23149172 